NBER WORKING PAPER SERIES

\title{
EARLY HEALTH SHOCKS, INTRAHOUSEHOLD RESOURCE ALLOCATION, AND CHILD OUTCOMES
}

\author{
Junjian Yi \\ James J. Heckman \\ Junsen Zhang \\ Gabriella Conti \\ Working Paper 20757 \\ http://www.nber.org/papers/w20757 \\ NATIONAL BUREAU OF ECONOMIC RESEARCH \\ 1050 Massachusetts Avenue \\ Cambridge, MA 02138 \\ December 2014
}

The research was supported in part by the American Bar Foundation, the Pritzker Children's Initiative, the Buffett Early Childhood Fund, NIH grants NICHD R37HD065072 and R01HD54702, an anonymous funder, an European Research Council grant (DEVHEALTH 269874), a grant for the FIS from the Chinese University of Hong Kong, and a grant from the Institute for New Economic Thinking (INET) to the Human Capital and Economic Opportunity Global Working Group (HCEO)-an initiative of the Becker Friedman Institute for Research in Economics (BFI). The views expressed in this paper are those of the authors and not necessarily those of the funders or persons named here. The views expressed herein are those of the authors and do not necessarily reflect the views of the National Bureau of Economic Research.

NBER working papers are circulated for discussion and comment purposes. They have not been peerreviewed or been subject to the review by the NBER Board of Directors that accompanies official NBER publications.

(C) 2014 by Junjian Yi, James J. Heckman, Junsen Zhang, and Gabriella Conti. All rights reserved. Short sections of text, not to exceed two paragraphs, may be quoted without explicit permission provided that full credit, including $(\mathcal{C}$ notice, is given to the source. 
Early Health Shocks, Intrahousehold Resource Allocation, and Child Outcomes

Junjian Yi, James J. Heckman, Junsen Zhang, and Gabriella Conti

NBER Working Paper No. 20757

December 2014

JEL No. C23,D13,I12,J13

\begin{abstract}
$\underline{\text { ABSTRACT }}$
An open question in the literature is whether families compensate or reinforce the impact of child health shocks. Discussions usually focus on one dimension of child investment. This paper examines multiple dimensions using household survey data on Chinese child twins whose average age is 11 . We find that, compared with a twin sibling who did not suffer from negative early health shocks at ages 0-3, the other twin sibling who did suffer negative health shocks received RMB 305 more in terms of health investments, but received RMB 182 less in terms of educational investments in the 12 months prior to the survey. In terms of financial transfers over all dimensions of investment, the family acts as a net equalizer in response to early health shocks for children. We estimate a human capital production function and establish that, for this sample, early health shocks negatively affect child human capital, including health, education, and socioemotional skills. Compensating investments in health as measured by BMI reduce the adverse effects of health shocks by $50 \%$, but exacerbate the adverse impact of shocks on educational attainment by $30 \%$.
\end{abstract}

Junjian Yi

Department of Economics, National University of Singapore

Faculty of Arts \& Social Sciences

AS2 Level 6, 1

Singapore 117570

junjian.yi@gmail.com

James J. Heckman

Department of Economics

The University of Chicago

1126 E. 59th Street

Chicago, IL 60637

and University College Dublin and IZA

and also NBER

jjh@uchicago.edu
Junsen Zhang

Department of Economics

Chinese University of Hong Kong

Shatin, N.T.

Hong Kong

jszhang@cuhk.edu.hk

Gabriella Conti

Department of Applied Health Research

University College London

1-19 Torrington Place

London WC1E 7HB

UK

gabriella.conti@ucl.ac.uk 


\section{Introduction}

The importance of the family in fostering child human capital is well understood by economists. How parents invest in children with different endowments is not wellstudied and there is no consensus in the literature. Becker and Tomes (1976) and Tomes (1981) suggest that parental investments reinforce initial endowments, and that such behavior increases inequality. Griliches (1979) conjectures that parental human capital investments compensate for gaps in children's endowments, and that the family is an equalizing agent. A number of empirical studies find evidence for reinforcing behaviors (Behrman, Rosenzweig, and Taubman, 1994; Rosenzweig and Zhang, 2009). Other studies find empirical support for compensating behaviors (Behrman, Pollak, and Taubman, 1982; Pitt, Rosenzweig, and Hassan, 1990).

This paper contributes to this literature. It studies how early health shocks to children affect intrahousehold resource allocation and the human capital formation of children. For two reasons, early health shocks in developing countries are likely to negatively affect children's human capital accumulation and long-run outcomes (Strauss and Thomas, 2007; Currie and Vogl, 2012). First, young children are especially vulnerable to health insults in developing countries. For example, more than $10 \%$ of children suffer from diarrhea in many developing countries such as Bangladesh (Strauss and Thomas, 1998). Second, in the absence of public health insurance and in the presence of pervasive poverty, a child affected by a health insult may not receive appropriate medical treatment. Consequently, early health shocks may have long-lasting consequences. In the absence of a well-functioning public education system, the consequences of an early health shock may be exacerbated and thus impair human capital formation (Glewwe and Miguel, 2007).

This paper formulates and estimates a theoretical model with two channels through which early health shocks affect child human capital formation. The first is a biological channel operating directly through the production function for human capital. The second is an intrahousehold resource allocation effect arising from parental responses to the shock. 
Parental responses to an early health shock on children may be more important in developing countries with weaker health infrastructure and less well-established credit markets and social protection systems. The absence of an old-age pension system and the presence of tight credit constraint may drive parents to base their intrahousehold resource allocation decisions on efficiency rather than on equity concerns. In this case, parents are more likely to reinforce the harmful effects of an early health insult by devoting less resources to the less-endowed child. The role of the family must be considered when designing public policies to remedy the effects of inequality at birth or the early childhood stage.

Following recent developments in the economics of human capital (Cunha and Heckman, 2007; Heckman, 2007; Cunha, Heckman, and Schennach, 2010), our theoretical analysis extends the conventional literature on intrahousehold resource allocation in two ways. First, we allow for multidimensionality in human capital. The conventional literature assumes a single dimension of human capital on which parents can compensate or reinforce. Borghans, Duckworth, Heckman, and ter Weel (2008a), Cunha, Heckman, and Schennach (2010), and Almlund, Duckworth, Heckman, and Kautz (2011) extend the analysis of human capital from a single dimension to multiple dimensions and emphasize the cross-productivity of different types of human capital. These studies focus on the human capital production process of individuals and do not explore the implications of multidimensionality of human capital for the intrahousehold resource allocation across children.

Second, we examine the interaction of parental preferences and the human capital production function in the intrahousehold resource allocation process. The conventional literature focuses on parental preferences and has made special assumptions about the role of human capital production in the intrahousehold resource allocation process. For example, Becker and Tomes (1976) and Pitt, Rosenzweig, and Hassan (1990) assume a linear production function with respect to child endowments, whereas Behrman, Pollak, and Taubman $(1982,1986)$ assume a Cobb-Douglas technology. Under both specifications, parental investment strategies are determined only by parental 
inequality aversion across children.

Our paper combines the traditional literature on intrahousehold resource allocation with recent developments in the economics of human capital. We demonstrate that parents can both reinforce and compensate human capital investment in different dimensions of human capital in children. Whether parents exhibit a reinforcing, compensating, or neutral investment strategy is ultimately an empirical question.

We shed light on these mechanisms by estimating the effect of child early health shocks on family investments. We use data from the Chinese Child Twins Survey (CCTS), which contains detailed information on family health and educational investments for each child separately whose average age is 11 . The sample is conducted in a rural region exempt from the one child policy. To the best of our knowledge, CCTS is the first census-type household survey on child twins around the world. We find evidence of compensating investments in child health and reinforcing investments in education in response to early health shocks for one twin child in the family. Our empirical results show that, compared with the twin sibling who did not suffer from negative early health shocks at ages $0-3$, the other twin sibling who did received RMB 305 more health investments in the 12 months prior to the survey. This amount is substantial and is more than one third of the average family investment in child education per year or about one half of maternal monthly wage. Offsetting this in a different dimension, on average, the sick child received RMB 182 less on educational investments than their twin siblings.

We estimate the child human capital production function. Holding constant family investments, the estimated coefficient on early health shocks in the production function reflects only a biological effect. We separate the biological effect from the intrahousehold resource allocation effect.

Because family investments are chosen and unobservables in choice and outcome equations are likely correlated, we correct for spurious correlation bias using 2SLS with price and non-labor income as instruments. Our estimates show that family investments have positive productivity effects and that early health insults negatively 
affect child outcomes, including health, education, and socioemotional skills.

We also estimate a human capital production function excluding family investments. These reduced-form estimates correspond to the total effects of early health shocks on child human capital. From them we can infer the importance of the intrahousehold resource allocation effect by comparing the reduced-form estimates with the estimates from the structural production function. We find that reduced-form estimates understate the biological effect by one-half for anthropometric measures, such as body mass index (BMI), but overstate the biological effect by one-third for a number of educational outcome measures.

Our findings have important policy implications. When parents simultaneously compensate in health investments and reinforce in educational investments across their children, the effect of family investments on inequality in the society becomes more nuanced. A multidimensional perspective on inequality is warranted. The overall level of inequality is overestimated if one focuses solely on inequality in education because inequality in health is reduced by family investments. Our estimates suggest that the Chinese family appears to be a net equalizer in terms of child human capital investment when both education and health are combined. Parental responses should be considered when designing intervention policies to remedy the disadvantaged children because parents can exacerbate or eliminate these effects by reallocating resources within the family.

Our results shed light on recent literature on the effect of early-life conditions on late-life outcomes (Case, Fertig, and Paxson, 2005; Almond and Currie, 2011). Although the literature has achieved a consensus on the negative effects of early-life health insults on both short-run (Currie, Stabile, Manivong, and Roos, 2010) and long-run outcomes (Smith, 2009), the role played by parental behavior remains unclear. The reduced-form estimates of the effect of early-life shocks that disregard intrahousehold responses do not necessarily represent a biological effect. When parents make compensating and reinforcing investments along different dimensions of human capital, the reduced-form estimates cannot be unambiguously interpreted as upper- 
or lower-bounds of biological effects. Our empirical analysis suggests that reducedform estimates of early health shocks on child health understate the biological effect, whereas those for child education overstate the biological effect. These results imply that caution must be taken in interpreting reduced-form estimates as biological effects and confirms the importance of considering parental behavioral response when studying the consequences of early-life health insults.

The remainder of the paper is organized as follows. We derive our theoretical model in Section 2. In Section 3, we describe the CCTS data used to test our theoretical prediction. Our econometric specification is presented in Section 4. We present the estimation results in Section 5 and conclude in Section 6.

\section{The Conceptual Framework}

This section analyzes child early health shocks, intrahousehold resource allocation, and child human capital formation. We show that an early health shock can affect child human capital through two channels: a direct channel (the biological effect through the production of human capital) and an indirect one (the intrahousehold resource allocation effect through parental responses). By introducing the multidimensionality of child human capital, we show that parents could compensate and reinforce along different dimensions of a child's human capital with respect to an early health shock on one child.

\subsection{The Model}

We assume that each family has two children $(\iota=i, j) .{ }^{1}$ Each child has a two components of human capital: health $(H)$ and a bundle of cognitive and socioemotional skills $(C)$. We treat the latter as an aggregate in this section. Child prenatal endowment such as birth weight is $\omega_{\iota}^{k}$; parental human capital investments is $I_{\iota}^{k}$, and child

\footnotetext{
${ }^{1}$ It is natural to extend the model to a general case with $n$ children in the family. However, fertility is a parental choice. Twinning combined with the one-child policy serves as a natural experiment that fertility is exogenous in our analysis, which is based on the CCTS.
} 
human capital is $\theta_{\iota}^{k}$, where $k=H, C$. We further denote a child's characteristics such as gender and ethnicity by $\xi$, and parental characteristics by $h$. The human capital production function of type $k$ for child $i$ in family $\tau$ is specified as follows:

$$
\theta_{i, \tau}^{k}=f^{k}\left(\omega_{i, \tau}^{H}, \omega_{i, \tau}^{C}, I_{i, \tau}^{k}, e_{i, \tau}^{H} ; \xi_{i, \tau}, h_{\tau}\right)
$$

where $e_{i, \tau}^{H}$ is defined as a postnatal negative health shock affecting child $i$ at early stages, and $\frac{\partial \theta_{i, \tau}^{k}}{\partial e_{i, \tau}^{H}}<0$. Child human capital is determined by the child's endowments, human capital investment, and health shocks. Parental and individual's characteristics also affect the formation of child human capital. The production technology of health differs from that of cognitive skills. The production function is the same for all children in family $\tau$, but may differ from one family to another. ${ }^{2}$

In Equation (1), we assume that the health shock of child $j$ does not directly enter child $i$ 's human capital production function, although $e_{j}^{H}$ can indirectly affect child $i$ 's human capital through parental investment. Thus, we assume away a contagious effect of early health shocks in the model, but we test this assumption in Appendix A. ${ }^{3}$ Second, we focus on health shocks; our data show that the most prevalent health shock is diarrhea.

Parents are assumed to value child outcomes. They also care about their own consumption and leisure. Parental preferences are represented by utility function:

$$
U=U\left(c, l, q_{i}, q_{j}\right)
$$

where $c$ is parental consumption, $l$ is parental leisure time, and $q_{\iota}$ is the quality of child $\iota$. Denoting $T$ as the parental labor supply and normalizing the parental time endowment to one, we have $l+T=1 .^{4}$ Child quality is a combination of health and cognitive skills

\footnotetext{
${ }^{2}$ We suppress the family subscript $\tau$ on the technology to simplify notation.

${ }^{3}$ In Appendix A, we show that early health shocks measured in our empirical analysis are non-infectious diarrhea.

${ }^{4}$ Economists have stressed the importance of parental tutoring time as a determinant of child human capital production. We ignore this argument in our analysis because the parental tutoring time in our sample is small, and we find little effect of early health shocks on parental tutoring time.
} 
such that $q_{\iota}=q\left(\theta_{\iota}^{H}, \theta_{\iota}^{C}\right)$. Both children have the same quality function. However, they may have different qualities because the endowments, early health shocks, and human capital investments could be different. The budget constraint is specified as follows:

$$
p_{I}\left(\sum_{\iota} \sum_{k} I_{\iota}^{k}\right)+c+w l=Y+w
$$

where $p_{I}$ is the price of human capital investment and is assumed to be independent of the type of investment; $w$ and $Y$ are parents' wage rate multiplied by time available (assumed to equal 1) and non-labor income. The price of parental consumption is normalized to one. We further assume that parents provide all the resources for their children's human capital. ${ }^{5}$

\subsection{Child Early Health Shock and Parental Responses}

We now analyze how parents adjust intrahousehold resource allocation in response to an early health shock on their children. The parents' problem is to maximize the utility function (2) subject to the budget constraint (3) and production technology (1). If the utility function and production function are strictly concave and continuously twice-differentiable, then the existence, uniqueness, and continuity of the solution to the intrahousehold resource allocation problem directly follow. We denote the optimal human capital investment of type $k$ in child $i$ as a function of the following form:

$$
I_{i}^{k *}=\psi^{k}\left(\omega_{i}^{H}, \omega_{i}^{C}, \omega_{j}^{H}, \omega_{j}^{C}, e_{i}^{H}, e_{j}^{H}, \xi_{i}, \xi_{j}, h, p_{I}, w, Y\right)
$$

A reinforcement strategy for investment of type $k$ arises if $\frac{\partial I_{i}^{k *}}{\partial e_{i}^{H}} \leq 0$ and $\frac{\partial I_{i}^{k *}}{\partial e_{j}^{H}} \geq 0$, i.e., parents put less investment of type $k$ in the child who has suffered from an early health shock and place more investment in the child if his or her twin sibling has suffered. In this case, $\frac{\partial I_{i}^{k *}}{\partial e_{i}^{H}}-\frac{\partial I_{i}^{k *}}{\partial e_{j}^{H}} \leq 0$. In contrast, if $\frac{\partial I_{i}^{k *}}{\partial e_{i}^{H}} \geq 0$ and $\frac{\partial I_{i}^{k *}}{\partial e_{j}^{H}} \leq 0$, we say that parents use a compensatory strategy in investment of type $k$ in children. Thus,

\footnotetext{
${ }^{5}$ This assumption is approximately valid in the context of developing countries where public education and medical insurance are absent, which is discussed in later sections.
} 
$\frac{\partial I_{i}^{k *}}{\partial e_{i}^{H}}-\frac{\partial I_{i}^{k *}}{\partial e_{j}^{H}} \geq 0$

The definition of reinforcing or compensating strategies does not presuppose any specific model of intrahousehold resource allocation. The parameters determining which type of strategy parents adopt depends on the specific model employed.

For example, Behrman, Pollak, and Taubman (1982) assume a Cobb-Douglas production function and a CES parental utility function. They show that the optimal investment strategy is uniquely determined by parental preference parameters. Conversely, Almond and Currie (2011) assume a CES production function and a CobbDouglas parental utility function. Thus, the optimal investment strategy is uniquely determined by production technology parameters. We show that, in general, the optimal investment strategy reflects a combination of parental preference and production technology in the general case.

In a more general model with multidimensional human capital, the child human capital investment strategy reflects not only parental preferences but also the production technology available to them. Parents can compensate and reinforce along different dimensions of human capital with respect to early health shocks.

Family investment can exacerbate inequality in one dimension but, at the same time, ameliorate inequality in another dimension. Our analysis does not impose particular functional forms. Appendix B discusses the consequences of specific choices further.

\subsection{Early Health Shocks, Parental Responses, and Child Human Capital}

Early health shocks affect child human capital through two different channels: a biological effect and a behavioral effect. From Equation (1), the total effect of an early health shock on child $i$ on the child's human capital $k$ can be decomposed as follows:

$$
\underbrace{\frac{d \theta_{i}^{k}}{d e_{i}^{H}}}_{A}=\underbrace{\frac{\partial \theta_{i}^{k}}{\partial e_{i}^{H}}}_{B}+\underbrace{\frac{\partial \theta_{i}^{k}}{\partial I_{i}^{k}}}_{C} \cdot \underbrace{\frac{\partial I_{i}^{k}}{\partial e_{i}^{H}}}_{D} .
$$


The term on the left hand side $(A)$ is the total effect of an early health shock, which corresponds to the reduced-form estimate in the literature. The first term on the right hand side $(B)$ is a biological effect that directly operates through the production function and is assumed to be negative. The second term $(C \cdot D)$ is a behavioral effect that operates through parental responses in adjusting family investment. The behavioral effect is the product of the productivity effect of the investment $(C)$ and the intrahousehold resource allocation effect $(D)$. In general, the effect of an early health shock is generally not the same as the biological effect. We assume that the productivity effect of family investment is positive, an assumption tested below. The sign of the behavioral effect is determined by the intrahousehold resource allocation effect, which cannot be determined a priori, and can vary across different dimensions of human capital.

The reduced-form estimate $(A)$ is interpreted as an upper- (lower-) bound of the biological effect if we know that the parents adopt a reinforcing (compensatory) strategy (which is characterized by the sign of $D$ ). We can separate the biological effect $(B)$ from the behavioral effect by estimating Equation (1) controlling for family investment. By comparing the estimate of the biological effect $(B)$ with the reduced-form estimate of the total effect $(A)$, we can quantify the importance of the behavioral response in family investments to account for the total effect of early health shocks on child human capital.

\subsection{Early Health Shocks, Parental Labor Supply, and Con- sumption}

Early health shocks to children could result in external effects on other family members. In this paper, we study the effect of early health shocks on parental labor supply and consumption. The optimal parental labor supply $\left(T^{*}\right)$ and parental consumption $\left(c^{*}\right)$ is a vector function of the following form:

$$
y=y\left(\omega_{i}^{H}, \omega_{i}^{C}, \omega_{j}^{H}, \omega_{j}^{C}, e_{i}^{H}, e_{j}^{H}, \xi_{i}, \xi_{j}, h, p_{I}, w, Y\right)
$$


where $y=\left(T^{*}, c^{*}\right)$. Adopting specific function forms in the example presented in Appendix B, we show that child early health shock decreases parental consumption but increases parental labor supply.

\section{Data}

\subsection{The Chinese Child Twins Survey (CCTS)}

The Chinese Child Twins survey (CCTS) was conducted by the Urban Survey Unit (USU) of the National Bureau of Statistics in late 2002 and early 2003 in Kunming, China. Kunming, which is the capital city of Yunnan Province, has a total population of approximately 5 million. Yunnan is a relatively under-developed province located in the far southwestern corner of China.

To the best of our knowledge, CCTS is the first census-type household survey on twin children. The survey includes almost all households with twins aged between 6 years and 18 years living in Kunming in 2002. The average age of the twin children is 11. The households have been initially identified by the USU on the basis of the 2000 population census according to whether the children have the same birth year and month and whether they have the same relationship with the household head. The addresses of these households are then obtained from the census office, and the presence of twins is verified with a visit to the household. Starting from 2,300 pairs of potential twins identified in the census, 1,694 households with twins are successfully interviewed. The survey covers an extensive range of information about family investment in each child separately and child outcomes, in addition to a wide range of demographic, social, and economic information at the household level. See Rosenzweig and Zhang (2009) for a detailed description of the CCTS. 


\subsection{Descriptive Statistics}

We now describe the variables in our data that are the empirical counterparts of those in the theoretical analysis. Table 1 tabulates the descriptive statistics. Early health shocks $\left(e^{H}\right)$ are defined by a dummy variable that indicates whether a child suffered from a serious disease from ages 0 to 3 . The complete list of diseases include serious diarrhea, calcium deficiency, asthma, fracture, attention deficit disorder, heart disease, serious hearing difficulties, whooping cough, stammer, and serious eyesight problems. The first three constitute $92 \%$ of the serious diseases suffered by children, and such a number is consistent with the case for children in developing countries. ${ }^{6,7}$ Table 1 shows that the prevalence rate of early health shocks in our sample is $9 \%$. We address potential concerns with various types of measurement errors in constructing the variable of child early health shocks in Appendix C.

\footnotetext{
${ }^{6}$ Strauss and Thomas (1998).

${ }^{7}$ Unfortunately, we cannot distinguish between mental and physical diseases because the former has low prevalence in our sample.
} 
Table 1: Descriptive Statistics

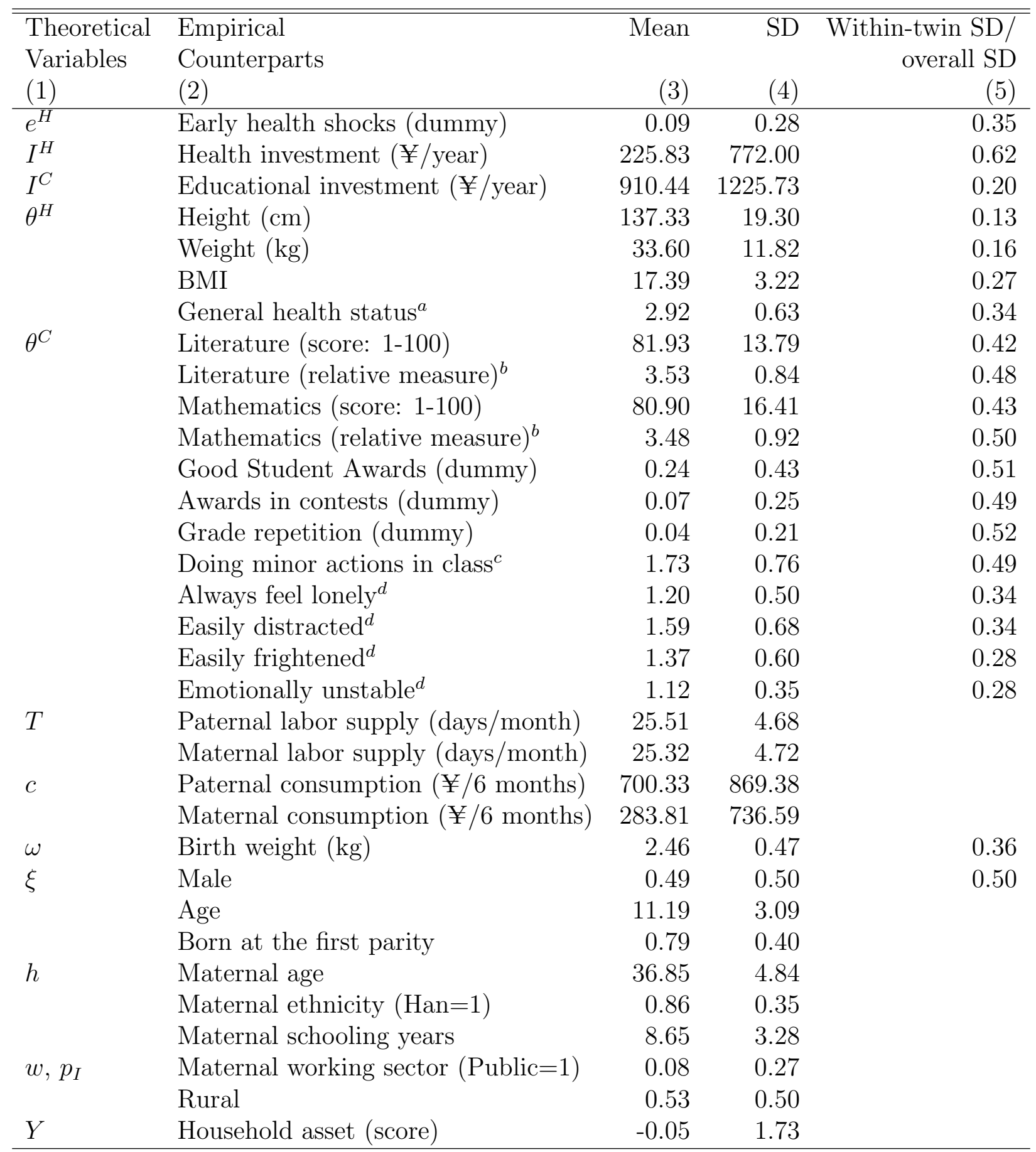

Note: The sample includes 1,456 pairs of twins. Column (5) presents the share of the withintwin standard deviation out of the overall sample standard deviation.

$a$ : 4-point Likert scale: 1 (worst) to 4 (best)

${ }^{b}: 1$ (top quintile in the class) to 5 (lowest quintile)

c: 4-point Likert scale: 1 (never) to 4 (always)

$d$ : 3-point Likert scale: 1 (disagree), 2 (agree), 3 (strongly agree) 
Our main dependent variables are measures of the family investments in children in the 12 months prior to the survey $\left(I^{\kappa}\right)$. The investments are separately recorded for each child. Health investments include money spent on medical treatments and on the purchase of medicine or health products. ${ }^{8}$ Educational investments include school tuition and money spent on purchasing books and stationery, hiring home tutors, and attending tutoring class. We note that the medical and educational investments on children constitute a substantial fraction of the family income. Educational investments on one child alone amount to RMB 912 per year out of a per capita family income of RMB 3,030 per year.

The CCTS covers rich information for measuring child human capital. As measures of child health $\left(\theta^{H}\right)$, we use anthropometric indicators (i.e., height, weight, and BMI) and general health status, which are all reported by both parents. We use child academic and schooling performance to measure child educational outcomes. As measures of academic performance (components of $\theta^{C}$ ), we use both objective (exam transcripts) and subjective (self-reported evaluations in comparison with the class norm) measures in two different subjects: literature and mathematics. They are compulsory courses from primary school to high school (from age 6 to 18). We also analyze several outcomes related to school performance, which are recorded from transcripts. They include good student awards, awards in contests, grade repetition, and whether the child often does naughty actions in class as reported by teachers.

Our data are also rich in terms of socioemotional measures, which are categorical and reported by both parents. We have four measures: always feels lonely, easily distracted, easily frightened, and emotionally unstable. These variables are derived from the Strengths and Difficulties Questionnaire (SDQ) used by CCTS. The SDQ is one of the most commonly used instruments for screening child psychiatric morbidities. See Du, Kou, and Coghill (2008) for the discussion on the reliability and validity on Asian children of SDQ.

We also analyze the effect of early health shocks on parental labor supply $(T)$

\footnotetext{
${ }^{8}$ Grossman (2000) also measures medical care by personal medical expenditures on doctors, dentists, hospital care, prescribed and nonprescribed drugs, nonmedical practitioners, and medical appliances.
} 
and consumption $(c)$. Parental labor supply is measured as days worked per month. Parental consumption is measured as the total expenditure on cigarettes, alcohol, clothes, and cosmetics in the past six months prior to the survey. The consumptions are separately recorded for mothers and fathers.

Birth weights are used to proxy child pre-birth endowments $(\omega)$. This variable is used to measure both health and cognitive endowments. We have three variables for measuring child characteristics $(\xi)$ : age, gender, and birth order. ${ }^{9}$ The variables of maternal age, ethnicity, and schooling years are used to proxy parental characteristics $(h)$.

We use both the rural hukou and maternal working sector to proxy wages $(w)$ and medical and educational prices $\left(p_{I}\right)$. The rural indicator is commonly used to proxy for wages in studies in developing countries because of the large wage gap between rural and urban areas (Johnson, 1947; Rosenzweig, 1980). We also use hukou to proxy the price of health services. At the time of the survey, the medical insurance system was almost completely absent in rural areas, whereas medical expenditures on children could be partly reimbursed for urban residents. Although public education is not free in both urban and rural areas at the time of the survey, the quality of education in urban areas is higher than that in rural areas. Note that Chinese residents find it difficult to change their hukou.

The maternal working sector is a good variable proxying for prices on health and educational investments. Child medical treatment and education are usually subsidized by the government if mothers are working in the public sector. Moreover, job turnover from public to private sectors is rare for Chinese women. We use household asset as a proxy for non-labor income $(Y)$. The household asset is a score generated by using the factor analysis (Kolenikov and Angeles, 2009). The durable goods used to generate the household asset scores include washing machine, refrigerator, air-conditioner, shower heater, water dispenser, sterilized cupboard, motorcycle, care, radio/recorder, color

\footnotetext{
${ }^{9}$ The one-child policy is strictly implemented in urban areas in Kunming. However, households in rural areas are encouraged to have one child, but are exempted from the strict one-child policy, although they are allowed to have two children at most (Family Planning Commission of Yunnan Province, 2003).
} 
television, video recorder, video displayer, hi-fi, camera, telephone, and mobile phone.

Finally, column (5) of Table 1 shows substantial within-twin-pair variations in early health shocks, family investments, and child outcomes. For example, the within-twin standard deviations accounts for about $35 \%$ of the total sample standard deviations of child early health shocks. This ratio is as high as $62 \%$ for child health investments.

\section{Our Econometric Model and Its Identification}

This section presents our econometric model and a discussion of how we identify it. We first analyze how parents respond to early child health shocks. We linearize the optimal human capital investment Equation (4) as a first-order approximation and add a disturbance term $\left(\epsilon_{i, \tau}^{k}\right)$, which is assumed to reflect measurement errors in the investment of type $k$ specific to child $i$ in family $\tau$; and assume that children are treated symmetrically (so that statistically they are exchangeable):

$$
I_{i, \tau}^{k}=\alpha_{1}^{k} e_{i, \tau}^{H}+\alpha_{2}^{k} e_{j, \tau}^{H}+\alpha_{3}^{k} \omega_{i, \tau}+\alpha_{4}^{k} \omega_{j, \tau}+\alpha_{5}^{k} \xi_{i, \tau}+\alpha_{6}^{k} \xi_{j, \tau}+\alpha_{7}^{k} \zeta_{\tau}+\left(\mu_{\tau}\right)+\epsilon_{i, \tau}^{k}
$$

The assumption of symmetry implies that the coefficients are the same across children. We normalize the coefficient on parental preferences $\left(\mu_{\tau}\right)$ to be $1 . \zeta_{\tau}$ is a vector of variables including the price for human capital investment $\left(p_{I}\right)$, wage rate $(w)$, nonlabor income $(Y)$, and other observable parental characteristics, which is denoted as $\kappa$. We denote $\mu$ as the unobserved parental characteristics or preferences. Thus, $h=(\kappa, \mu)$. Both $\zeta_{\tau}$ and $\mu_{\tau}$ are shared by twin siblings. Unlike Equation (4), we do not make the distinction between health and cognitive endowments because we have only one variable - birth weight - to measure prenatal endowment in our data set. Conditioning on the unobservable $\mu_{\tau}$, we further assume $\epsilon_{i, \tau}^{k}$ to be i.i.d.

The major problem in identifying the own effect $\left(\alpha_{1}^{k}\right)$ and cross effect $\left(\alpha_{2}^{k}\right)$ of an early health shock on family investment is that the early health shock may reflect unobserved parental preferences $\mu_{\tau}$. For example, on the one hand, parents who prefer child human capital may be more likely to report that their children have suffered 
from early health shocks even if their children did not. On the other hand, these parents may spend more on human capital investments. In this case, the least squares estimates of Equation (7), ignoring unobserved parental characteristics or preferences, would be biased. If the cross-sibling effects are symmetric and equal, we can eliminate this source of bias by the following within-twin fixed-effects (FE) estimator:

$$
\Delta I_{\tau}^{k}=\left(\alpha_{1}^{k}-\alpha_{2}^{k}\right) \Delta e_{\tau}^{H}+\left(\alpha_{3}^{k}-\alpha_{4}^{k}\right) \Delta \omega_{\tau}+\left(\alpha_{5}^{k}-\alpha_{6}^{k}\right) \Delta \xi_{\tau}+\Delta \epsilon_{\tau}^{k},
$$

where $\Delta$ is an operator of within-twin difference. We test the symmetric regression assumption of cross-sibling effects below and find that it is not rejected in our data.

We are interested in the estimates of $\alpha_{1}^{k}-\alpha_{2}^{k}$ in Equation (8) which reflect parental investment strategy or the intrahousehold resource allocation effect of human capital investment of type $k$. If parents reinforce investment of type $k$ in response to an early health shock on child $i$, then $\alpha_{1}^{k}-\alpha_{2}^{k}<0$; compensation implies that $\alpha_{1}^{k}-\alpha_{2}^{k}>0$. The self and cross effects reflect the interaction between parental preference and production technology. Our theory predicts that parents could make compensating and reinforcing investments along different dimensions of human capital in response to an early health shock. Therefore, the signs of $\alpha_{1}^{H}-\alpha_{2}^{H}$ and $\alpha_{1}^{C}-\alpha_{2}^{C}$ are not necessarily the same.

Our basic identifying assumption is that the within-twin variation in the error term of Equation (8) is uncorrelated with the within-twin variation in early health shocks. This assumption may not necessarily hold. For example, the within-twin difference in individual specific prenatal endowment might not be fully controlled for by $\Delta \omega$, leading to a correlation between $\Delta e$ and $\Delta \epsilon$. If so, $\Delta e$ would be endogenous in Equation (8), and the OLS estimates of Equation (8) would be biased. ${ }^{10}$

We measure early health shocks by serious diseases at ages 0-3 as discussed in the section above. Diseases can either reflect a random shock which is consistent with the definition of early health shocks in the model, or be an indication of an individualspecific health endowment. In other words, though early health shocks may or may not

\footnotetext{
${ }^{10}$ A similar issue has been extensively investigated in the literature on twin-based estimation of returns to schooling (Griliches, 1979; Bound and Solon, 1999; Neumark, 1999).
} 
be exogenous in Equation (7), what we need for identification is that the within-twin variation in early health shocks is random and exogenous in Equation (8).

We propose and implement a test to examine the identifying assumption. We assume that the unobservables in health shocks are uniform across children with a family and that elimination of a family fixed effect eliminates any spurious correlation. A test of this assumption compares the OLS estimates of the coefficients of (7) for the sick and healthy child. The difference in the OLS estimates should accord with the fixed effect estimates assuming all other covariates are equally correlated with the health shocks.

Specifically, under the null hypothesis that within-twin variations in early health shocks are exogenous such that $e_{\iota}^{H}$ and $\epsilon$ are uncorrelated in Equation (7) after controlling for the unobservable $\mu_{\tau}$, we have (1) plim $\widehat{\alpha}_{1}^{k}=\alpha_{1}^{k}+\frac{\sigma_{\mu, e_{i}^{H}}}{\sigma_{e_{i}^{H}}^{2}}$ and plim $\widehat{\alpha}_{2}^{k}=\alpha_{2}^{k}+\frac{\sigma_{\mu, e_{j}^{H}}}{\sigma_{e_{j}^{H}}^{2}}$ in Equation (7), where $\sigma_{\mu, e_{\iota}^{H}}$ is the covariance of of $\mu$ (family fixed effects) and $e_{\iota}^{H}$ (early health shock for child $\tau$ ), and $\sigma_{e_{\iota}^{H}}^{2}$ is the variance of $e_{\iota}^{H} ; 11$ (2) $\frac{\sigma_{\mu, e_{i}^{H}}}{\sigma_{e_{i}^{H}}^{2}}=\frac{\sigma_{\mu, e_{j}^{H}}}{\sigma_{e_{j}^{H}}^{2}}$ by symmetry; (3) plim $\left(\widehat{\alpha_{1}^{k-\alpha}} \alpha_{2}^{k}\right)=\alpha_{1}^{k}-\alpha_{2}^{k}$ in Equation (8). Therefore, the null hypothesis of symmetry (really exchangeability) gives the cross-equation restriction:

$$
\operatorname{plim}\left(\widehat{\alpha}_{1}^{k}-\widehat{\alpha}_{2}^{k}\right)=\operatorname{plim}\left(\widehat{\alpha_{1}^{k-\alpha}} \alpha_{2}^{k}\right) .
$$

where $\widehat{\alpha}_{1}^{k}$ and $\widehat{\alpha}_{2}^{k}$ are the OLS estimates of Equation (7), and $\left(\widehat{\alpha_{1}^{k-}-\alpha_{2}^{k}}\right)$ are the fixedeffects estimates of Equation (8). Thus, we test differences of estimates obtained from OLS versus estimates obtained from a fixed-effects procedure. If there are unobservable individual-specific prenatal endowments and $e_{\iota}^{H}$ and $\epsilon$ are correlated in Equation (7), the null hypothesis of symmetry and the equality in Equation (9) would not hold. ${ }^{12}$ We test and do not reject this restriction in our empirical analysis reported below.

We then analyze the effect of early health shocks on child human capital. By

\footnotetext{
${ }^{11}$ We ignore other covariates in the equation to simplify our discussion. We further assume that no contagious effect of early health shocks exists. The result below stands if the contagious effect is symmetric between twin siblings.

${ }^{12}$ The cross-equation restriction also applies if $e^{H}$ is measured with errors which are related to family investment behavior. See the discussion in Appendix C.
} 
linearizing the production function (1) as a first-order approximation and by adding a disturbance term that reflects measurement errors $\left(u_{i, \tau}\right)$, which are individual-specific, we specify the following regression equation:

$$
\theta_{i, \tau}^{k}=\beta_{1}^{k} e_{i, \tau}^{H}+\beta_{2}^{k} \omega_{i, \tau}+\beta_{3}^{k} I_{i, \tau}^{k}+\beta_{4}^{k} \xi_{i, \tau}+\beta_{5}^{k} \kappa_{\tau}+\mu_{\tau}+v_{i, \tau}
$$

where $\kappa$ denotes observable parental characteristics. The cross-sectional variation in early health shocks may reflect the unobservable parental characteristics. For example, better child-rearing practice may lead to less early health shocks and, at the same time, more child human capital. To remove the possible bias induced by unobserved parental characteristics, we use the following Fixed Effect (FE) specification:

$$
\Delta \theta_{\tau}^{k}=\beta_{1}^{k} \Delta e_{\tau}^{H}+\beta_{2}^{k} \Delta I_{\tau}^{k}+\beta_{3}^{k} \Delta \omega_{\tau}+\beta_{4}^{k} \Delta \xi_{\tau}+\Delta v_{\tau}
$$

where $\beta_{1}^{k}$ captures the biological effects corresponding to the first term on the righthand side of Equation (5), which is expected to be negative; $\beta_{2}^{k}$ measures the productivity effect of family investments, which is expected to be positive.

Because family investment is a parental choice, we need to worry about simultaneous equations bias. We use a 2SLS method to estimate Equation (11). The theoretical analysis guides us to choose the instrumental variable (IV). The price of investments $\left(p_{I}\right)$, wage rate $(w)$, and non-labor income $(Y)$ in the family investment equation (4) are excluded from the production function (1). However, these variables drop out from the within-twin differences of Equation (11). We thus use $p_{I}, w$, and $Y$ interacted with the within-twin variation in child prenatal endowment and characteristics $(\Delta \omega * Y$, $\Delta \omega * p_{I}, \Delta \omega * h, \Delta \xi * Y, \Delta \xi * p_{I}$, and $\left.\Delta \xi * h\right)$ as IVs for within-twin variation in investments $\left(\Delta I^{k}(k=H, C)\right)$ in Equation (11). Specifically, we use two types of interaction terms as IVs for within-twin difference in health or educational investment. The first type includes the interaction terms between the within-twin difference in birth weight and the household and parental level variables, and the second type includes the interaction terms between the within-twin difference in gender and the household 
and parental level variables. The household and parental level variables include a rural indicator, maternal working sector, age, ethnicity, and schooling years.

Administrative data usually do not have information on family investments in children's human capital. Thus, the recent literature on health economics does not estimate health production functions. Instead, the literature specifies a reduced-form regression equation that ignores the intrahousehold response such as:

$$
\Delta \theta_{\tau}^{k}=\phi_{1}^{k} \Delta e_{\tau}^{H}+\phi_{2}^{k} \Delta \omega_{\tau}+\phi_{3}^{k} \Delta \xi_{\tau}+\Delta u_{\tau}
$$

The reduced-form estimate of $\phi_{1}^{k}$ captures the total effect of an early health shock on child human capital, and corresponds to the left hand side of Equation (5). When

$\beta_{2}^{k} \neq 0$ and $\alpha_{1}^{k}-\alpha_{2}^{k} \neq 0, \beta_{1}^{k}$ differs from $\phi_{1}^{k}$. The total effect deviates from the biological effect. To compare our results with those in the literature, we also perform the reduced-form estimation in our empirical analysis. By comparing $\beta_{1}^{k}$ with $\phi_{1}^{k}$, we can qualitatively infer the importance of the intrahousehold resource allocation effects by using Equation (5).

\section{Empirical Evidence}

\subsection{Child Early Health Shock and Family Investments}

Before presenting the estimation results of the investment equation, we first examine the determinants of early health shocks. The results are reported in Table 2. Column (1) reports the OLS estimates. We find that low birth weight is positively correlated with the probability of suffering early health shocks. We also observe that males are more likely to suffer. Results also show a positive correlation between maternal schooling and the probability of reporting children suffering from early health shock. We interpret this positive correlation as a reporting bias that is commonly found in the literature on health economics (Strauss and Thomas, 1998). If the reporting bias is determined by parental observed and unobserved characteristics, the issue of reporting 
bias can be addressed by the within-twin FE estimation because these parental characteristics are removed by within-twin differences. The FE estimates in column (2) show that the occurrence of an early health shock is unrelated to birth weight. In column (3), we report regression of the within-twin difference in early health shocks on both within-twin differences in birth weight and gender and other level covariates. We find that the within-twin variations in early health shocks are uncorrelated with the level variables. Therefore, the results in Table 2 do not reject our identifying assumption of the randomness of within-twin variation in early health shocks. 
Table 2: Determinants of Child Early Health Shocks

\begin{tabular}{llll}
\hline \hline & \multicolumn{3}{l}{ Dependent variable: } \\
& \multicolumn{3}{l}{ Early health shocks } \\
\cline { 2 - 4 } & $(1)$ & $(2)$ & $(3)$ \\
\hline \multirow{2}{*}{ Birth weight: $<2 \mathrm{~kg}$} & $0.044^{* *}$ & 0.020 & 0.021 \\
& {$[0.020]$} & {$[0.022]$} & {$[0.022]$} \\
Birth weight: $2-2.5 \mathrm{~kg}$ & 0.008 & -0.000 & 0.001 \\
& {$[0.016]$} & {$[0.018]$} & {$[0.018]$} \\
Birth weight: $2.5-3 \mathrm{~kg}$ & -0.012 & -0.024 & -0.022 \\
& {$[0.016]$} & {$[0.015]$} & {$[0.015]$} \\
Male & $0.040^{* * *}$ & $0.020^{*}$ & $0.020^{*}$ \\
& {$[0.010]$} & {$[0.010]$} & {$[0.010]$} \\
Age & -0.001 & & 0.001 \\
& {$[0.002]$} & & {$[0.002]$} \\
Born at the first parity & 0.008 & & -0.007 \\
& {$[0.014]$} & & {$[0.014]$} \\
Maternal age & -0.002 & & -0.000 \\
Maternal ethnicity (Han $=1)$ & {$[0.001]$} & & {$[0.001]$} \\
Maternal schooling years & -0.014 & & 0.013 \\
& {$[0.015]$} & & {$[0.015]$} \\
Maternal working sector (public $=1)$ & $0.007^{* * *}$ & & -0.000 \\
& {$[0.002]$} & & {$[0.002]$} \\
Rural & {$[0.022]$} & & 0.012 \\
& -0.019 & & $-0.021]$ \\
Household asset & {$[0.013]$} & & {$[0.014$} \\
& $-0.007^{*}$ & & 0.004 \\
$R^{2}$ & {$[0.004]$} & & {$[0.004]$} \\
\# Pair of twins & & & \\
\hline
\end{tabular}

Note: Columns (1) and (2) report the OLS and within-twin fixed-effects estimates, respectively. In column (3), we regress the within-twin differences in early health shock on both within-twin differences in birth weight and gender and other variables at the household level. Standard errors are in brackets; ${ }^{*}$ significant at $10 \% ;{ }^{* *}$ significant at $5 \%$; ${ }^{* *}$ significant at $1 \%$.

We now turn to our main estimation results about child early health shocks and family investments in children. Column (1) in Table 3 reports the OLS estimates 
of Equation (7) with respect to health investments. We find that the own effect of an early health shock on the health investment is significantly positive, whereas the cross-sibling effect is almost zero. We also find that being a male, being born at first parity, maternal schooling years, and household asset are positively correlated with child health investments. By contrast, the variable of "born in rural areas" is negatively correlated with child health investment.

To test the symmetry assumption of cross-sibling effects, we use the same sample as in column (1), but employ the family health investment in child $j$ as a dependent variable. The results are reported in column (2). We then conduct a Wald test. The $\chi^{2}$ statistic is 18.87 , and the $p$-value is 0.34 . These findings indicate that we cannot reject the symmetry assumption. Therefore, we conduct an FE estimation of Equation (8) with respect to health investments. The results are reported in column (3). On the basis of these estimates, we find that the gap in health expenditures on average increases by $\mathrm{RMB} 305(1.39 * 225)$ in favor of the sick twin child, which amounts to more than one third of the average family investment in child education per year. 
Table 3: Child Early Health Shocks and Parental Investment in Health

\begin{tabular}{|c|c|c|c|}
\hline & $\begin{array}{l}\text { Dependent variable } \\
\text { Health investment } \\
\text { in child } i(\log ) \\
(1)\end{array}$ & $\begin{array}{l}\text { Health investment } \\
\text { in child } j(\log ) \\
(2)\end{array}$ & $\begin{array}{l}\text { Difference in } \\
\text { Health investment } \\
(3)\end{array}$ \\
\hline Early health shocks $(i)$ & $1.192^{* * *}$ & -0.288 & $1.349^{* * *}$ \\
\hline & {$[0.325]$} & {$[0.312]$} & {$[0.243]$} \\
\hline Early health shocks $(j)$ & 0.001 & $1.194^{* * *}$ & \\
\hline & {$[0.322]$} & {$[0.309]$} & \\
\hline Birth weight: $<2$ kg $(i)$ & 0.113 & -0.297 & $0.534^{* * *}$ \\
\hline & {$[0.286]$} & {$[0.275]$} & {$[0.204]$} \\
\hline Birth weight: $2-2.5 \mathrm{~kg}(i)$ & 0.237 & -0.286 & $0.484^{* * *}$ \\
\hline & {$[0.232]$} & {$[0.223]$} & {$[0.163]$} \\
\hline Birth weight: $2.5-3 \mathrm{~kg}(i)$ & 0.248 & -0.192 & $0.418^{* * *}$ \\
\hline & {$[0.213]$} & {$[0.204]$} & {$[0.139]$} \\
\hline Birth weight: $<2 \mathrm{~kg}(j)$ & 0.203 & $0.889^{* * *}$ & \\
\hline & {$[0.289]$} & {$[0.277]$} & \\
\hline Birth weight: $2-2.5 \mathrm{~kg}(j)$ & 0.054 & $0.463^{* *}$ & \\
\hline & {$[0.227]$} & {$[0.218]$} & \\
\hline Birth weight: $2.5-3 \mathrm{~kg}(j)$ & -0.073 & $0.317^{*}$ & \\
\hline & {$[0.200]$} & {$[0.192]$} & \\
\hline Male $(i)$ & $0.291^{* *}$ & $0.226^{*}$ & 0.071 \\
\hline & {$[0.137]$} & {$[0.132]$} & {$[0.095]$} \\
\hline Male $(j)$ & 0.021 & 0.087 & \\
\hline & {$[0.137]$} & {$[0.132]$} & \\
\hline Age & $-0.041^{*}$ & $-0.046^{* *}$ & \\
\hline & {$[0.024]$} & {$[0.023]$} & \\
\hline Born at the first parity & $0.387^{* *}$ & $0.361^{* *}$ & \\
\hline & {$[0.162]$} & {$[0.155]$} & \\
\hline Maternal age & 0.007 & 0.003 & \\
\hline & {$[0.015]$} & {$[0.015]$} & \\
\hline Maternal ethnicity $(\mathrm{Han}=1)$ & 0.006 & 0.102 & \\
\hline & {$[0.173]$} & {$[0.166]$} & \\
\hline Maternal schooling years & $0.083^{* * *}$ & $0.114^{* * *}$ & \\
\hline & {$[0.024]$} & {$[0.023]$} & \\
\hline Maternal working sector $($ public $=1)$ & -0.286 & -0.378 & \\
\hline & {$[0.246]$} & {$[0.237]$} & \\
\hline Rural & $-0.298^{* *}$ & 0.047 & \\
\hline & {$[0.145]$} & {$[0.139]$} & \\
\hline Household asset & $0.124^{* * *}$ & 0.067 & \\
\hline & {$[0.045]$} & {$[0.043]$} & \\
\hline$\chi^{2}$ & & 18.87 & 0.14 \\
\hline$p$-values & & 0.34 & 0.71 \\
\hline \# Pair of twins & 1,456 & 1,456 & 1,456 \\
\hline
\end{tabular}

Note: Columns (1) and (2) report the OLS estimates; column (3) reports the within-twin fixed-effect estimates. Standard errors are in brackets; ${ }^{*}$ significant at $10 \%$; ${ }^{*}$ significant at $5 \%$; *** significant at $1 \%$. 
To test the null hypothesis that within-twin variations in early health shocks are exogenous such that $\Delta e$ and $\Delta \epsilon$ are uncorrelated in Equation (8), we conduct a Wald test on Equation (9). If any individual specific component is omitted from Equation (8) such that $\Delta e$ and $\Delta \epsilon$ are correlated, within-twin variations in early health shocks would be endogenous. Thus, the equality in Equation (9) would break down. We report the test result at the end of column (3). The $\chi^{2}$ statistic is 0.14 , and the $p$-value is 0.71 . Therefore, the null hypothesis is not rejected.

Table 4 presents the estimates on child early health shock and family educational investment. Column (1) reports the ordinary least square (OLS) estimates of Equation (7) with respect to educational investments. In contrast to the estimates with health investments (column (1) in Table 3), we find that the own effect of an early health shock on educational investment is not statistically significant, although the estimate is negative. In contrast, we find that the cross-sibling effect is positive. The other covariates, namely, child age, maternal age, maternal schooling years, and household asset are significantly positively correlated with child educational investments, whereas the covariate "born in rural areas" is negatively correlated with child educational investment.

The result of testing the symmetry assumption of cross-sibling effects is reported at the end of column (2). The $\chi^{2}$ statistic is 19.39 with a $p$-value of 0.31 . We cannot reject the symmetry assumption. Therefore, we conduct the FE estimation of Equation (8) with respect to educational investments. The results are reported in column (3). We find that, in contrast to the estimates with health investment, the gap in educational expenditures increases by RMB $182\left(0.2^{*} 910\right)$, on average, in favor of the healthy child. The $\chi^{2}$ statistic of testing the cross-equation restriction (Equation (9)) is 0.70, and the $p$-value is 0.41 . We cannot reject the null hypothesis that no endogenous within-twin variation exists in early health shock.

Summarizing Tables 3 and 4, our results indicate that parents adopt a compensating strategy with respect to health investment and a reinforcing strategy with respect to educational investment in response to an early health shock which affects one of the 
twin children.

We also estimate the family investment equation by different subsamples based on hukou status, maternal education, household wealth, and gender composition of twin children. We find significant differences in the compensating and reinforcing patterns across subsamples. First, the increase in health expenditures in favor of the sick twin in rural areas is not accompanied by a corresponding decrease in educational expenditures. In urban areas, instead, the fall in the amount of educational resources on the sick child almost exactly offsets, in monetary terms, the amount redistributed to pay for the medical expense. Second, both the compensating health investment and the reinforcing education investment are more precisely determined when mothers have a higher education level. Third, there is no significant difference in the compensating health investment behavior between poor and rich households. In contrast, the reinforcing education investment behavior is more significant in rich households that that in poor households. Finally, we find significant differences by gender. The compensating health investment and the reinforcing education investment are more significant in the female twin than male twin samples. The results are reported and discussed in Appendix D. 
Table 4: Child Early Health Shocks and Parental Investment in Education

\begin{tabular}{|c|c|c|c|}
\hline & $\begin{array}{l}\text { Dependent variable: } \\
\text { Education investment } \\
\text { in child } i(\log ) \\
(1)\end{array}$ & $\begin{array}{l}\text { Education investment } \\
\text { in child } j(\log ) \\
(2)\end{array}$ & $\begin{array}{l}\text { Difference in } \\
\text { Education investment }\end{array}$ \\
\hline Early health shocks $(i)$ & & $\frac{(2)}{0.065}$ & $\frac{-0204 x}{(0)}$ \\
\hline & {$[0.131]$} & {$[0.124]$} & $\begin{array}{l}-0.204 \\
{[0.047]}\end{array}$ \\
\hline Early health shocks $(j)$ & $\begin{array}{l}0.213 \\
{[0.130]}\end{array}$ & $\begin{array}{l}0.008 \\
{[0.123]}\end{array}$ & \\
\hline Birth weight: $<2 \mathrm{~kg}(i)$ & $\begin{array}{l}0.012 \\
{[0.115]}\end{array}$ & $\begin{array}{l}0.059 \\
{[0.110]}\end{array}$ & $\begin{array}{l}-0.015 \\
{[0.039]}\end{array}$ \\
\hline Birth weight: $2-2.5 \mathrm{~kg}(i)$ & $\begin{array}{l}0.131 \\
{[0.094]}\end{array}$ & $\begin{array}{l}0.123 \\
{[0.089]}\end{array}$ & $\begin{array}{l}0.016 \\
{[0.031]}\end{array}$ \\
\hline Birth weight: $2.5-3 \mathrm{~kg}(i)$ & $\begin{array}{l}0.007 \\
{[0.086]}\end{array}$ & $\begin{array}{l}0.031 \\
{[0.081]}\end{array}$ & $\begin{array}{l}-0.013 \\
{[0.027]}\end{array}$ \\
\hline Birth weight: $<2 \mathrm{~kg}(j)$ & $\begin{array}{l}-0.143 \\
{[0.117]}\end{array}$ & $\begin{array}{l}-0.127 \\
{[0.111]}\end{array}$ & \\
\hline Birth weight: $2-2.5 \mathrm{~kg}(j)$ & $\begin{array}{l}-0.060 \\
{[0.091]}\end{array}$ & $\begin{array}{l}-0.045 \\
{[0.087]}\end{array}$ & \\
\hline Birth weight: $2.5-3 \mathrm{~kg}(j)$ & $\begin{array}{l}-0.098 \\
{[0.081]}\end{array}$ & $\begin{array}{l}-0.103 \\
{[0.077]}\end{array}$ & \\
\hline Male $(i)$ & $\begin{array}{l}-0.042 \\
{[0.055]}\end{array}$ & $\begin{array}{l}-0.014 \\
{[0.053]}\end{array}$ & $\begin{array}{l}-0.024 \\
{[0.018]}\end{array}$ \\
\hline Male $(j)$ & $\begin{array}{l}0.027 \\
{[0.055]}\end{array}$ & $\begin{array}{l}0.008 \\
{[0.053]}\end{array}$ & \\
\hline Age & $\begin{array}{l}0.083^{* * *} \\
{[0.010]}\end{array}$ & $\begin{array}{l}0.088^{* * *} \\
{[0.009]}\end{array}$ & \\
\hline Born at the first parity & $\begin{array}{l}0.042 \\
{[0.065]}\end{array}$ & $\begin{array}{l}0.041 \\
{[0.062]}\end{array}$ & \\
\hline Maternal age & $\begin{array}{l}0.014^{* *} \\
{[0.006]}\end{array}$ & $\begin{array}{l}0.014^{* *} \\
{[0.006]}\end{array}$ & \\
\hline Maternal ethnicity $(\operatorname{Han}=1)$ & $\begin{array}{l}0.090 \\
{[0.070]}\end{array}$ & $\begin{array}{l}0.111^{*} \\
{[0.066]}\end{array}$ & \\
\hline Maternal schooling years & $\begin{array}{l}0.038^{* * *} \\
{[0.010]}\end{array}$ & $\begin{array}{l}0.041^{* * *} \\
{[0.009]}\end{array}$ & \\
\hline Maternal working sector $($ public $=1$ ) & $\begin{array}{l}0.083 \\
{[0.099]}\end{array}$ & $\begin{array}{l}0.024 \\
{[0.094]}\end{array}$ & \\
\hline Rural & $\begin{array}{l}-0.150^{* *} \\
{[0.058]}\end{array}$ & $\begin{array}{l}-0.184^{* * *} \\
{[0.055]}\end{array}$ & \\
\hline Household asset & $\begin{array}{l}0.130^{* * *} \\
{[0.018]}\end{array}$ & $\begin{array}{l}0.124^{* * *} \\
{[0.017]}\end{array}$ & \\
\hline$\chi^{2}$ & & 19.39 & 0.70 \\
\hline$p$-values & & 0.31 & 0.41 \\
\hline \# Pair of twins & 1,456 & 1,456 & 1,456 \\
\hline
\end{tabular}

Note: Columns (1) and (2) report the OLS estimates; column (3) reports the within-twin fixed-effect estimates. Standard errors are in brackets; ${ }^{*}$ significant at $10 \%$; ${ }^{*}$ significant at $5 \%$; $* * *$ significant at $1 \%$. 
Our results have important implications. First, the results are consistent with our two major observations in the theoretical analysis on the intrahousehold resource allocation. The reinforcement or compensatory child human capital investment strategy reflects not only parental preference but also production technology. Furthermore, parents can compensate and reinforce along different dimensions of human capital with respect to an early health shock on one child, which helps us reconcile the seemingly conflict findings in the literature.

Second, the results deepen our understanding of the role of family investment in the overall level of inequality in a society. Our estimates indicate that intrahousehold resource reallocation in child investment is not trivial. The gap in educational investment between sick and healthy children accounts for up to one-fifth of the average educational investment per person. The gap in health investment is even larger. Therefore, the family plays an important role in accounting for the difference in investment in children. However, the role of family in this case is complicated. On the one hand, parents increase the gap in educational investment by allocating more resources to the child suffering from early health shock. In this regard, the family increases the overall level of inequality in the economy. On the other hand, parents decrease the gap in health investment by allocating more resource on the sick child. Thus, in terms of health investment, family decreases inequality. If we focus on educational investment, then the role of family as an inequality mitigator may be understated.

Finally, our empirical results clarify the interpretation of the recent reduced-form estimates on early-life conditions and late-life outcomes. When parents make compensating and reinforcing investments along different dimensions of human capital, these reduced-form estimates cannot be unambiguously interpreted as upper- or lowerbounds of the biological effects. Our estimates on intrahousehold resource allocation suggest that the reduced-form estimates underestimate the biological effect of an early health shock on health, but overestimate the biological effect on education. To empirically verify this prediction, we estimate the child human capital production function below. 


\subsection{Early Health Shocks and Child Human Capital}

\subsubsection{Child Health}

We next examine the effects of early health shock on child human capital by estimating the production function (11). Health investment is an endogenous variable in the child human capital equation. As discussed above, we use a 2SLS estimator. Guided by our theoretical model, we use $\Delta \omega * Y, \Delta \omega * p_{I}, \Delta \omega * h, \Delta \xi * Y, \Delta \xi * p_{I}$, and $\Delta \xi * h$ as the IVs for $\Delta I^{k}(k=H, C)$ in Equation (11). Specifically, the IVs include the interaction terms between the within-twin variations in birth weights and gender and the level variables, which include a rural indicator, maternal working sector, age, ethnicity, and schooling. The results in Table 2 show that these level variables are uncorrelated with the within-twin variation in early health shocks.

The first panel in Table 5 reports the 2SLS estimates of the child health production function. ${ }^{13}$ Conditional on the health investment, the estimate of early health shock captures the biological effect. We find a long-lasting negative biological effect of early health shocks on the child's later health status. The estimates are statistically significant at a high level of $1 \%$ for three out of four measures. We also find that the productivity effects of the health investment are consistently positive. The estimates are statistically significant at the $5 \%$ level for current weight and BMI.

To compare our results with those from the recent literature in health economics and to qualitatively gauge the importance of intrahousehold resource allocation effect, we also estimate the reduced-form of Equation (12). Table 3 shows that parents take a compensatory investment strategy in health investments, and the intrahousehold resource allocation effect is positive. The first panel of Table 5 shows a significantly positive productivity effect of health investment. By using the formula of Equation (5), we expect that the reduced-form estimates understate the biological effect of early health shock on later health status.

This prediction is confirmed by the reduced-form estimates, which are reported in

\footnotetext{
${ }^{13}$ We report only the estimated coefficients on early health shock and health investment in the paper. The full results are reported in Appendix E.
} 
the second panel of Table 5. The reduced-form estimates are also consistently negative, indicating that the direct biological effects, which are negative, outweigh the positive intrahousehold resource allocation effects. We find that the reduced-form estimates substantially underestimate the biological effects. Take the dependent variable of BMI as an example (column (3)), the reduced-form estimate (-0.20) accounts for one half of the biological effect (-0.40). Almost the same proportion of the negative biological effect $(-0.42)$ is accounted for by the reduced-form estimate $(-0.26)$ with respect to weight (column (2)). The results have important implications, suggesting that although the negative effect of an early health shock may persist throughout the life-cycle of children, remediation is possible. In other words, the negative effects can be partly offset by compensating investments within the household.

\section{Table 5: Early Health Shocks and Child Health}

\begin{tabular}{lllll}
\hline \hline & \multicolumn{3}{l}{ Dependent variables: } \\
& $\begin{array}{l}\text { Height } \\
z \text {-score }\end{array}$ & $\begin{array}{l}\text { Weight } \\
\text {-score }\end{array}$ & $\begin{array}{l}\text { BMI } \\
\text {-score }\end{array}$ & $\begin{array}{l}\text { Health } \\
\text { status }\end{array}$ \\
\cline { 2 - 5 } & $(1)$ & $(2)$ & $(3)$ & $(4)$ \\
\hline & \multicolumn{5}{c}{ 2SLS estimates } \\
\cline { 2 - 5 } Early health shocks & -0.100 & $-0.422^{* * *}$ & $-0.395^{* * *}$ & $-0.513^{* * *}$ \\
& {$[0.130]$} & {$[0.118]$} & {$[0.151]$} & {$[0.078]$} \\
Health investments ${ }^{a}$ & 0.070 & $0.118^{* *}$ & $0.160^{* *}$ & 0.047 \\
& {$[0.064]$} & {$[0.059]$} & {$[0.077]$} & {$[0.039]$} \\
\hline & \multicolumn{5}{c}{ Reduced-form estimates } \\
\cline { 2 - 5 } Early health shocks & -0.004 & $-0.263^{* * *}$ & $-0.201^{*}$ & $-0.449^{* * *}$ \\
& {$[0.096]$} & {$[0.086]$} & {$[0.113]$} & {$[0.057]$} \\
\hline \# Pair of twins & 1,418 & 1,430 & 1,408 & 1,450 \\
\hline
\end{tabular}

Note: Standard errors are in brackets; ${ }^{*}$ significant at $10 \% ;{ }^{* *}$ significant at $5 \%$; ${ }^{* *}$ significant at $1 \%$. Birth weight and child gender are controlled for in each regression.

${ }^{a}$ : Endogenous variable. The instrumental variables include two types of interaction terms. The first type includes the interaction terms between the within-twin difference in birth weight and the household and parental level variables, and the second type includes the interaction terms between the within-twin difference in gender and the level variables. The household and parental level variables include a rural indicator, maternal working sector, age, ethnicity, and schooling years. 


\subsubsection{Child Education and Socioemotional Skills}

We next examine the effects of an early health shock on child education by estimating the child education production function (11). The same set of variables are used as IVs for educational investment as discussed above. Panel 1 in Table 6 reports the 2SLS estimates of early health shocks on child educational achievements, both perceived and actual. We find that the twin child affected by an early health insult has poorer academic achievement compared with the healthy child. The productivity effects of educational investments on academic achievements are consistently positive across the four measures, but are generally imprecisely estimated. We also conduct the 2SLS estimation of early health shocks on child schooling performance. The results are reported in the third panel of the table, which shows that an early health insult negatively affects the child's schooling performance. We further observe that educational investments exert a positive productivity effect on the child's schooling performance.

The reduced-form estimates are reported in Panels 2 and 4. We find that the reduced-form estimates are consistently larger than the 2SLS estimates in terms of absolute values. The result suggests that the reduced-form estimates overstate the negative biological effect of early health shocks on child education. By comparing the 2SLS estimates with the reduced-form estimates, we find that the biological effects constitute a major part of the total effect for most measures of child educational outcomes. The result suggests a strong cross-productivity effect of health shocks on education, as reported in Cunha, Heckman, and Schennach (2010). The intrahousehold resource allocation effect has also played an important role. Take the transcript recorded score

of literature as an example (column (1)), the intrahousehold resource allocation effect accounts for about one-third of the total negative effect of an early health shock. 


\section{Table 6: Early Health Shocks and Child Education}

\begin{tabular}{|c|c|c|c|c|}
\hline & \multicolumn{4}{|c|}{ Dependent variables: } \\
\hline & score & relative measure & score & relative measure \\
\hline & (1) & $(2)$ & $(3)$ & $(4)$ \\
\hline & \multicolumn{4}{|c|}{ 2SLS estimates } \\
\hline \multirow[t]{2}{*}{ Early health shocks } & $-3.990^{*}$ & -0.168 & $-4.697^{*}$ & $-0.496^{* * *}$ \\
\hline & {$[2.045]$} & {$[0.145]$} & {$[2.432]$} & {$[0.157]$} \\
\hline \multirow[t]{2}{*}{ Educational investments ${ }^{a}$} & 6.124 & $0.904^{* *}$ & 3.598 & 0.170 \\
\hline & {$[6.313]$} & {$[0.426]$} & {$[7.459]$} & {$[0.466]$} \\
\hline \multirow[b]{2}{*}{ Early health shocks } & \multicolumn{4}{|c|}{ Reduced-form estimates } \\
\hline & $\begin{array}{l}-5.142^{* * *} \\
{[1.665]}\end{array}$ & $\begin{array}{l}-0.352^{* * *} \\
{[0.110]}\end{array}$ & $\begin{array}{l}-5.372^{* * *} \\
{[1.996]}\end{array}$ & $\begin{array}{l}-0.531^{* * *} \\
{[0.127]}\end{array}$ \\
\hline \multirow[t]{5}{*}{ \# Pair of twins } & 1,355 & 1,426 & 1,332 & 1,420 \\
\hline & \multicolumn{4}{|c|}{ Dependent variables: } \\
\hline & Good Student & Awards in & Grade & Doing minor \\
\hline & Awards & Contests & Repetition & actions in class \\
\hline & $(5)$ & $(6)$ & $(7)$ & $(8)$ \\
\hline & & 2SLS est & mates & \\
\hline \multirow[t]{2}{*}{ Early health shocks } & $-0.199^{* * *}$ & -0.067 & 0.025 & $0.296^{* *}$ \\
\hline & {$[0.072]$} & {$[0.042]$} & {$[0.038]$} & {$[0.121]$} \\
\hline \multirow[t]{2}{*}{ Educational investments ${ }^{a}$} & 0.075 & 0.103 & $-0.235^{* *}$ & $-0.639^{*}$ \\
\hline & {$[0.216]$} & {$[0.126]$} & {$[0.113]$} & {$[0.387]$} \\
\hline \multirow{3}{*}{ Early health shocks } & \multicolumn{4}{|c|}{ Reduced-form estimates } \\
\hline & $-0.215^{* * *}$ & $-0.088^{* * *}$ & $0.073^{* *}$ & $0.396^{* * *}$ \\
\hline & {$[0.058]$} & {$[0.033]$} & {$[0.029]$} & {$[0.101]$} \\
\hline \# Pair of twins & 1,456 & 1,456 & 1,456 & 1,440 \\
\hline
\end{tabular}

Note: Standard errors are in brackets; ${ }^{*}$ significant at $10 \%$; ** significant at $5 \%$; ${ }^{* *}$ significant at $1 \%$. Birth weight and child gender are controlled for in each regression.

${ }^{a}$ : Endogenous variable. The instrumental variables include two types of interaction terms. The first type includes the interaction terms between the within-twin difference in birth weight and the household and parental level variables, and the second type includes the interaction terms between the within-twin difference in gender and the level variables. The household and parental level variables include a rural indicator, maternal working sector, age, ethnicity, and schooling years. 
With regard to the effect of early health shocks on child socioemotional skills, Panel 1 in Table 7 reports the 2SLS estimates. The importance of these skills in determining an individual's income and other well-beings has been increasingly recognized by economists (Borghans, Duckworth, Heckman, and ter Weel, 2008b). We find that the twin child who suffered from early health shock at ages 0-3 has inferior personality traits. When we use the SWQ to measure the child's socioemotional skills, the estimates show that children who experienced early health shock are more likely to feel lonely, be easily distracted, easily frightened, and be emotionally unstable. Although the estimates of productivity effects of educational investment are consistently negative, the estimates are only statistically significant in column (3) with the measure of being easily frightened. The results suggest that educational investment may not be an important determinant of the development of socioemotional skills. ${ }^{14}$ Panel 2 reports the reduced-form estimates. By comparing the reduced-form estimates with the 2SLS estimates, we find that biological effects constitute a major part of the total effects except for the measure of being easily frightened (column (3)).

\footnotetext{
${ }^{14}$ Cunha, Heckman, and Schennach (2010) also use the education investment as the augment in the production function of socioemotional skills.
} 


\section{Table 7: Early Health Shocks and Child Socioeconomic Skills}

\begin{tabular}{|c|c|c|c|c|}
\hline & \multicolumn{4}{|c|}{ Dependent variables: } \\
\hline & $\begin{array}{l}\text { Feel } \\
\text { lonely }\end{array}$ & $\begin{array}{l}\text { Easily } \\
\text { distracted }\end{array}$ & $\begin{array}{l}\text { Easily } \\
\text { frightened }\end{array}$ & $\begin{array}{l}\text { Emotional } \\
\text { instable }\end{array}$ \\
\hline & $(1)$ & $(2)$ & $(3)$ & $(4)$ \\
\hline & \multicolumn{4}{|c|}{ 2SLS estimates } \\
\hline \multirow[t]{2}{*}{ Early health shocks } & $0.132^{* * *}$ & $0.121^{* *}$ & 0.066 & $0.085^{* * *}$ \\
\hline & {$[0.041]$} & {$[0.056]$} & {$[0.046]$} & {$[0.024]$} \\
\hline \multirow[t]{2}{*}{ Educational investments $^{a}$} & -0.158 & -0.150 & $-0.383^{* * *}$ & -0.113 \\
\hline & {$[0.123]$} & {$[0.166]$} & {$[0.139]$} & {$[0.073]$} \\
\hline \multirow{3}{*}{ Early health shocks } & \multicolumn{4}{|c|}{ Reduced-form estimates } \\
\hline & $0.165^{* * *}$ & $0.151^{* * *}$ & $0.144^{* * *}$ & $0.108^{* * *}$ \\
\hline & {$[0.032]$} & {$[0.044]$} & {$[0.033]$} & {$[0.019]$} \\
\hline \# Pair of twins & 1,456 & 1,456 & 1,456 & 1,456 \\
\hline
\end{tabular}

Note: Standard errors are in brackets; ${ }^{*}$ significant at 10\%; ${ }^{* *}$ significant at 5\%; ${ }^{* * *}$ significant at $1 \%$. Birth weight and child gender are controlled for in each regression.

${ }^{a}$ : Endogenous variable. The instrumental variables include two types of interaction terms. The first type includes the interaction terms between the within-twin difference in birth weight and the household and parental level variables, and the second type includes the interaction terms between the within-twin difference in gender and the level variables. The household and parental level variables include a rural indicator, maternal working sector, age, ethnicity, and schooling years.

\subsection{Child Early Health Shock and Parental Labor Supply and Consumptions}

Finally, we investigate how an early health shock on one child affects parental labor supply and consumption. We specify the following regression equation:

$$
y_{\tau}=\varphi_{1} d+\varphi_{2} \bar{\omega}_{\tau}+\varphi_{3} \xi_{\tau}+\zeta_{\tau} \varphi_{4}+v_{\tau}
$$

where $y_{\tau}$ measures parental labor supply or consumption in household $\tau$; $d$ is a dummy variable indicating whether the household has only one twin child who suffered from early health shock; $\bar{\omega}$ is the average birth weight of the twin children. Equation (13) is 
a linear approximation of the optimal parental labor supply or consumption function (6) with slight modifications. First, we estimate Equation (13) for mothers and fathers separately. We use the mean of birth weights to measure child prenatal endowments. Child characteristics are the same between twin siblings except for gender. We then use two dummy variables to measure children gender composition. The first variable indicates that both children are boys, and the other variable indicates that both are girls. Second, given that within-twin variation in early health shock is uncorrelated with the unobservable characteristics, which is tested above (Table 2), we add $d$ in the regression equation. Thus, $\varphi_{1}$ renders us a causal interpretation even if we ignore the unobservable parental characteristics when estimating Equation (13). Finally, the added disturbance term $v_{\tau}$ reflects measurement errors.

The estimation results are reported in Table 8. We find that in households with only one twin child who suffered from early health shock, the father is significantly less likely to spend money on goods for himself, and the mother is significantly more likely to work. Therefore, if we take other family members except the twin children into account, then our results imply that the within-twin FE estimates of child outcomes understate the overall negative effect of an early health shock in a family. 
Table 8: Child Early Health Shocks and Parental Labor Supply and Consumption

\begin{tabular}{|c|c|c|c|c|}
\hline & \multicolumn{4}{|c|}{ Dependent variables: } \\
\hline & \multicolumn{2}{|c|}{ Labor supply } & \multicolumn{2}{|c|}{ Consumption } \\
\hline & Father & Mother & Father & Mother \\
\hline & (1) & (2) & (3) & $(4)$ \\
\hline \multirow[t]{2}{*}{ Early health shocks } & -0.048 & $0.054^{* *}$ & $-128.808^{*}$ & 27.751 \\
\hline & {$[0.078]$} & {$[0.024]$} & {$[77.978]$} & {$[73.685]$} \\
\hline \multirow[t]{2}{*}{ Child birth weights (mean) } & 0.015 & 0.002 & $77.850^{*}$ & 27.692 \\
\hline & {$[0.020]$} & {$[0.014]$} & [44.919] & {$[30.173]$} \\
\hline \multirow[t]{2}{*}{ Child age } & -0.000 & 0.005 & -8.672 & -9.728 \\
\hline & {$[0.004]$} & {$[0.005]$} & {$[7.799]$} & {$[7.860]$} \\
\hline \multirow[t]{2}{*}{ Male twins } & 0.005 & -0.017 & -60.571 & -22.393 \\
\hline & {$[0.023]$} & {$[0.021]$} & {$[54.827]$} & {$[28.318]$} \\
\hline \multirow[t]{2}{*}{ Female twins } & -0.023 & -0.034 & -28.210 & 42.148 \\
\hline & {$[0.022]$} & {$[0.021]$} & [57.334] & {$[38.050]$} \\
\hline \multirow[t]{2}{*}{ Born at the first parity } & -0.003 & $-0.049^{* *}$ & -15.817 & 4.098 \\
\hline & {$[0.026]$} & {$[0.023]$} & [43.038] & {$[30.684]$} \\
\hline \multirow[t]{2}{*}{ Age } & -0.003 & -0.005 & $-13.630^{* * *}$ & $-5.438 * *$ \\
\hline & {$[0.002]$} & {$[0.004]$} & [3.359] & {$[2.629]$} \\
\hline \multirow[t]{2}{*}{ Ethnicity $(\operatorname{Han}=1)$} & $-0.028^{*}$ & $-0.030^{*}$ & -47.481 & -127.626 \\
\hline & {$[0.016]$} & {$[0.016]$} & [59.532] & {$[97.041]$} \\
\hline \multirow[t]{2}{*}{ Schooling years } & -0.007 & 0.001 & 0.218 & $29.564^{*}$ \\
\hline & {$[0.005]$} & {$[0.004]$} & [11.718] & [16.167] \\
\hline \multirow[t]{2}{*}{ Working in public sector } & -0.012 & $-0.054^{* * *}$ & 21.079 & $294.633^{* *}$ \\
\hline & {$[0.028]$} & {$[0.021]$} & [101.420] & [141.145] \\
\hline \multirow[t]{2}{*}{ Rural } & 0.017 & 0.017 & 40.632 & 82.299 \\
\hline & {$[0.018]$} & {$[0.016]$} & [55.064] & [58.220] \\
\hline \multirow[t]{2}{*}{ Household asset } & -0.004 & -0.010 & $230.205^{* * *}$ & $125.220^{* * *}$ \\
\hline & {$[0.006]$} & {$[0.007]$} & [29.027] & {$[13.827]$} \\
\hline \# Households & 1,158 & 1,044 & 1,416 & 1,437 \\
\hline
\end{tabular}

Note: Columns (1)-(4) reports the OLS estimates. Standard errors are in brackets; ${ }^{*}$ significant at $10 \%$; $* *$ significant at $5 \%$; $* * *$ significant at $1 \%$.

\section{Conclusions}

This paper studies how child early health shocks affect intrahousehold resource allocation and child human capital formation. We formulate a theoretical model that early health shocks can affect human capital through two channels: a direct channel - the biological effect through the production of human capital - and an indirect one - the intrahousehold resource allocation effect through parental responses. By introducing 
multidimensionality of human capital, parents could compensate and reinforce along different dimensions with respect to early health shocks on children. By using the CCTS data, we find evidence of compensating investment in child health but of reinforcing investment in education. We further estimate the child human capital production function. The results confirm that early health insults negatively affect child human capital, ranging from health and education to socioemotional skills. Reduced-form estimates, which ignore intrahousehold allocation process, understate the biological effect for health, but overstate the biological effect for some educational outcomes.

Our results have important implications for evaluating the role of the family in the overall inequality in the economy. When parents can simultaneously reinforce and compensate family investments on children along different dimensions of human capital, the effects of intrahousehold resource allocation on inequality become complicated. On the basis of our estimates, we conclude that the family appears to be a net equalizer in terms of family investment in financial terms. Our findings also emphasize the importance of accounting for parental behavioral responses to early health shocks. Intrahousehold responses should be considered when designing public interventions to remediate negative health shocks on children, because parents can partly offset the effect of public interventions by reallocating resources within the family.

Future research on the intrahousehold resource allocation and human capital formation is desirable. First, with recent progress on human capital production technology, estimating a structural model separating production technology from parental preference would be valuable. This approach is difficult because any structural parameter of production technology can be re-parameterized as parental preference and vice-versa. We would need exogenous variations in either parental preference or production technology to solve the identification problem. Second, consistent with the empirical literature based on sibling or twin data, our regression analyses use linear specifications. Relaxing the linearity specification in the estimation would be fruitful. However, this approach relies on the development of the econometrics of non-linear fixed-effects estimators. Finally, fertility decisions should be explicitly introduced in 
the next generation of models of intrahousehold resource allocation. 


\section{References}

Almlund, M., A. L. Duckworth, J. J. Heckman, and T. Kautz (2011): "Personality Psychology and Economics," in Handbook of the Economics of Education, ed. by E. Hanushek, S. Machin, and L. Woessman, vol. 4, pp. 1-181. Elsevier, Amsterdam.

Almond, D., And J. Currie (2011): "Human capital development before age five," Handbook of Labor Economics, 4B, 1315-1486.

Becker, G., AND N. Tomes (1976): "Child endowments and the quantity and quality of children," The Journal of Political Economy, 84(4), 143-162.

Behrman, J., R. Pollak, And P. Taubman (1982): "Parental preferences and provision for progeny," The Journal of Political Economy, 90(1), 52-73.

Behrman, J., M. Rosenzweig, and P. Taubman (1994): "Endowments and the allocation of schooling in the family and in the marriage market: the twins experiment," The Journal of Political Economy, 102(6), 1131-1174.

Behrman, J. R., R. A. Pollak, and P. Taubman (1986): "Do parents favor boys?," International Economic Review, 27(1), 33-54.

Borghans, L., A. L. Duckworth, J. J. Heckman, and B. ter Weel (2008a): "The Economics and Psychology of Personality Traits," Journal of Human Resources, 43(4), 972-1059.

- (2008b): "The Economics and Psychology of Personality Traits," IZA Discussion Paper, (3333), http://ftp.iza.org/dp3333.pdf.

Bound, J., And G. Solon (1999): "Double trouble: on the value of twins-based estimation of the return to schooling," Economics of Education Review, 18(2), 169182. 
Case, A., A. Fertig, And C. Paxson (2005): "The Lasting Impact of Childhood Health and Circumstance," Journal of Health Economics, 24(2), 365-389.

Cunha, F., J. Heckman, And S. Schennach (2010): "Estimating the technology of cognitive and noncognitive skill formation," Econometrica, 78(3), 883-931.

Cunha, F., And J. J. Heckman (2007): "The Technology of Skill Formation," American Economic Review, 97(2), 31-47.

Currie, J., M. Stabile, P. Manivong, and L. Roos (2010): "Child Health and Young Adult Outcomes," Journal of Human Resources, 45(3), 517.

Currie, J., And T. Vogl (2012): "Early-life health and adult circumstance in developing countries," Discussion paper, National Bureau of Economic Research.

Du, Y., J. Kou, And D. Coghill (2008): "The validity, reliability and normative scores of the parent, teacher and self report versions of the Strengths and Difficulties Questionnaire in China," Child and Adolescent Psychiatry and Mental Health, 2(1), 8.

Family Planning Commission of Yunnan Province (2003): "Regulations on Population and Family Planning in Yunnan Province," China Population Press.

Glewwe, P., And E. Miguel (2007): "The impact of child health and nutrition on education in less developed countries," Handbook of development economics, 4, $3561-3606$.

Griliches, Z. (1979): "Sibling Models and Data in Economics: Beginnings of a Survey," Journal of Political Economy, 87(5), S37-S64.

Grossman, M. (2000): "The Human Capital Model," in Handbook of Health Economics, ed. by A. J. Culyer, and J. P. Newhouse, vol. 1, pp. 347-408. Elsevier, Amsterdam. 
Heckman, J. J. (2007): "The Economics, Technology and Neuroscience of Human Capability Formation," Proceedings of the National Academy of Sciences, 104(3), $13250-13255$.

Johnson, D. G. (1947): Forward Prices for Agriculture. University of Chicago Press.

Kolenikov, S., And G. Angeles (2009): "Socioeconomic status measurement with discrete proxy variables: Is principal component analysis a reliable answer?," Review of Income and Wealth, 55(1), 128-165.

Neumark, D. (1999): "Biases in twin estimates of the return to schooling," Economics of Education Review, 18(2), 143-148.

Pitt, M., M. Rosenzweig, And M. Hassan (1990): "Productivity, health, and inequality in the intrahousehold distribution of food in low-income countries," The American Economic Review, 80(5), 1139-1156.

Rosenzweig, M. (1980): "Neoclassical theory and the optimizing peasant: An econometric analysis of market family labor supply in a developing country," The Quarterly Journal of Economics, 94(1), 31-55.

Rosenzweig, M., And J. Zhang (2009): "Do Population Control Policies Induce More Human Capital Investment? Twins, Birth Weight and China's OneChild?Policy," Review of Economic Studies, 76(3), 1149-1174.

Smith, J. (2009): "The impact of childhood health on adult labor market outcomes," The Review of Economics and Statistics, 91(3), 478-489.

Strauss, J., And D. Thomas (1998): "Health, nutrition, and economic development," Journal of Economic Literature, 36(2), 766-817.

Strauss, J., And D. Thomas (2007): "Health over the life course," Handbook of development economics, 4, 3375-3474. 
Tomes, N. (1981): "The family, inheritance, and the intergenerational transmission of inequality," The Journal of Political Economy, pp. 928-958. 